\title{
Multi-drug Resistant (MDR) and Extended Spectrum $\beta$-lactamase (ESBL) Producing Salmonella species isolated from fresh chicken liver samples
}

\section{Sanjib Adhikari}

Tribhuvan University - Birendra Multiple Campus https://orcid.org/0000-0002-5874-2547

\section{Sujan Khadka ( $\nabla$ sukha11@yahoo.com)}

https://orcid.org/0000-0003-1451-7804

\section{Sanjeep Sapkota}

Tribhuvan University - Birendra Multiple Campus

\section{Biplove Raj Sharma}

Tribhuvan University - Birendra Multiple Campus

\section{Anjita Ghimire}

Tribhuvan University - Birendra Multiple Campus

\section{Muna Chalise}

Tribhuvan University - Birendra Multiple Campus

\section{Devika Gurung}

Tribhuvan University - Birendra Multiple Campus

\section{Sujan Kunwar}

Tribhuvan University - Birendra Multiple Campus

\section{Research note}

Keywords: Salmonella, Fresh chicken liver samples, Antibiotic Susceptibility Test, Multi-drug Resistance, Extended Spectrum $\beta$-lactamase

Posted Date: October 1st, 2019

DOI: https://doi.org/10.21203/rs.2.15361/v1

License: (c) (1) This work is licensed under a Creative Commons Attribution 4.0 International License. Read Full License 


\section{Abstract}

Objective: Emergence of antibiotic resistance among microbes contaminating the fresh meat and meat products is a global public health concern as they can be easily transmitted to humans through their consumption and contact. The current study aimed to isolate and identify Salmonella sp. from fresh chicken liver samples and determine their antibiotic susceptibility patterns with special emphasis on multidrug resistance (MDR) and extended spectrum beta-lactamase (ESBL) production.

Results: Out of 200 samples analyzed, 61 (30.5\%) samples harbored Salmonella species among which 15 (7.5\%) samples showed the presence of Salmonella Typhi isolates. A significant association was noted in the incidence of Salmonella with various factors pertaining to the butchers such as age, sex and literacy rate. Salmonella isolates were highly sensitive to amikacin (82.0\%) and least sensitive to tetracycline (3.3\%). All the isolates were resistant to colistin. Moreover, 56 isolates were identified as multidrug-resistant. The total number of ESBL producers reported among Salmonella isolates was 29 (47.5\%). The study reported the presence of antibiotic-resistant Salmonella species in fresh chicken liver samples sold in Bharatpur metropolis suggesting a need of serious attention by the concerned authorities.

Keywords: Salmonella , Fresh chicken liver samples, Antibiotic Susceptibility Test, Multi-drug Resistance, Extended Spectrum $\beta$-lactamase

\section{Introduction}

Avian Salmonella infections are important causes of clinical disease in poultry and a potential source of foodborne transmission of Salmonella in human [1]. About $95.0 \%$ of salmonellosis cases were estimated to originate from food materials [2] and the colonization of Salmonella covers humans and animals including livestock, poultry, rodents and birds [3][4]. The adaptive ability of pathogen itself, the changing characteristics of the population, the increasing globalization of the food trade, and the changes in industrial structure, poor hygienic environment, improper storage or cooking, cross-contamination, infected stocks contribute to the development of Salmonella in poultry and poultry products leading to the major source of human foodborne illness and loss of product shelf-life [5][6].

Poultry products have always topped the incidence of salmonellosis in India, Egypt, Brazil, Zimbabwe, Nepal and other developing countries [7][8] and are the most seriously perceived food risks in chicken meat, even in the developed countries [9]. The incidence of human salmonellosis has increased greatly over the past 20 years and this can mostly be attributed to epidemics of $S$. enteritidis in poultry in numerous countries [10][11]. Salmonella serotypes differ significantly in their pathogenic potentials and a study suggested the confirmed cases of Salmonella sp. in the surveillance network FoodNet from the period 1996-2006 [12]. Chicken liver is an important low-cost source of animal protein, rich in nutrients, phosphorus, others minerals, and B-complex vitamins [13]; however, the presence of MDR resistant Salmonella sp. in chicken livers have become the solemn concern of food safety and one of the major 
public health problems [14][15][16]. Different food items have been documented as a reservoir of ESBL producing bacteria and such food items are probable sources for the acquirement of beta-lactamaseproducing bacteria. The frequency of isolation of Salmonella strains resistant to several antimicrobial agents has increased in several countries worldwide including Nepal [17][18][8]. Thus, the purpose of the present study was to determine the prevalence of MDR and ESBL producing Salmonella sp. from chicken livers sold at different slaughter houses in Bharatpur.

\section{Main Text}

A cross-sectional study was carried out among the slaughter houses of Bharatpur Metropolis, Nepal and laboratory analyses were performed at the Microbiology laboratory of Birendra Multiple Campus from February to June 2018. Random sampling was done to collect 200 non-repeated single meat samples from different slaughterhouses located at different places of Bharatpur (Baseni, Dipendra chowk, Hope chowk, Junhal road, Bel chowk, Malpot Chowk and Gitanagar). The sample size was determined in accordance with the incidence rate based on the previous study [8]. Each butcher was briefed of the purpose of sample collection and verbal informed consent was taken assuring them of total confidentiality. Slaughterhouse's sanitary and salubrious status was studied by brief interview using semi-structured questionnaire and through observations as well.

\section{Methodology}

Fresh chicken liver samples were collected separately in sterile zip-locked plastic bags with the help of sterile forceps and scissors, stored in cold box and transported aseptically to the laboratory for further processing within an hour. The samples were ground in sterile mortar and pestle to make fine particles and $1 \mathrm{~g}$ of them was inoculated into $9 \mathrm{ml}$ of distilled water and dilutions up to $10^{-5}$ were made. From each of $10^{-3}, 10^{-4}$ and $10^{-5}$ dilutions, $0.1 \mathrm{ml}$ of inoculum was spread in nutrient agar plates in triplicate and incubated at $37^{\circ} \mathrm{C}$ for $24 \mathrm{~h}$ to obtain viable count of the bacteria. For the isolation of Salmonella, 1 $\mathrm{ml}$ of the inoculum was enriched in Selenite F-broth (Himedia, M025S) and incubated at $37^{\circ} \mathrm{C}$ for $24 \mathrm{~h}$. A loopful of culture in Selenite F-broth was directly streaked on XLD agar (Himedia, MH031) and incubated at $37^{\circ} \mathrm{C}$ for $24 \mathrm{~h}$. Black-centered red colonies on XLD agar were sub-cultured on NA plates at $37^{\circ} \mathrm{C}$ for $24 \mathrm{~h}$ to obtain pure culture of the isolates [19]. For further identification of Salmonella species, Gram staining and various biochemical tests (SIM, MR-VP, citrate, catalase, oxidase, urease and TSI) were performed. A slide agglutination test using antisera (Statens serum institute, Copenhagen) was used to detect $S$. Typhi 09, poly $\mathrm{O}$ and $\mathrm{H}$ antigens.

All the isolates were tested for susceptibility to antimicrobial agents on MHA by Modified Kirby-Bauer disc diffusion method as recommended by the Clinical Laboratory Standards Institute. The antibiotic discs used were amikacin $(30 \mu \mathrm{g})$, cotrimoxazole $(25 \mu \mathrm{g})$, ciprofloxacin $(5 \mu \mathrm{g})$, colistin $(10 \mu \mathrm{g})$, tetracycline (30 $\mu \mathrm{g})$, gentamicin $(10 \mu \mathrm{g})$ and azithromycin $(15 \mu \mathrm{g})$. The turbidity of inoculums from a pure culture of Salmonella isolates on NA plates incubated at $37^{\circ} \mathrm{C}$ for $24 \mathrm{~h}$ were adjusted to the equivalent turbidity of 
0.5 McFarland standards before spreading uniformly over the surface of Mueller-Hinton agar (MHA) (Titan Biotech Ltd. Bhiwadi-301019, Rajasthan, India) plates. Using sterile tweezers, the antibiotic discs were placed widely spaced aseptically on the surface of MHA plate. The organism was classified as resistant, intermediate or sensitive according to the interpretative chart [20]. Resistance to more than three structural classes of the antimicrobials tested was considered as MDR [21]. Salmonella Typhimurium ATCC 14028 was used as a reference strain for quality control purposes.

Primary screening test for ESBL production was done by using ceftazidime and cefotaxime discs against which the organisms showing the zone of inhibition $\leq 22 \mathrm{~mm}$ for ceftazidime (CAZ) ( $30 \mu \mathrm{g})$ and $\leq 27 \mathrm{~mm}$ for cefotaxime (CTX) $(30 \mu \mathrm{g})$ were considered to be probable ESBL producers. The phenotypic confirmatory test was done for suspected ESBL producing isolates for which antibiotics combinations of ceftazidime + clavulanic acid (CAZ/CAC) $(30 / 10 \mu \mathrm{g})$ and cefotaxime + clavulanic acid (CTX/CTC) (30/10 $\mu \mathrm{g}$ ) were used according to the protocols recommended by CLSI [22]. An increase in the zone of inhibition by $\geq 5 \mathrm{~mm}$ around the discs containing cephalosporin with clavulanate over the discs containing cephalosporin alone were ESBL producers [22].

The data obtained from laboratory investigation were tabulated and presented in defined tables and $\mathrm{p}$ value of the obtained results was calculated using SPSSv20 software. P-value $\leq 0.05$ was considered to have a significant association.

\section{Results}

Total viable counts for the collected samples ranged from $7.8 \times 10^{4}-1.9 \times 10^{7}$. Among 200 fresh chicken liver samples, 61 (30.5\%) showed the growth of Salmonella sp. while $139(69.5 \%)$ didn't. Of 61 Salmonella species, 15 (7.5\%) were identified as $S$. Typhi.

\section{Association of different attributes of butchers with the contamination of meat by Salmonella species}

Salmonella species were isolated from 51 (28.2\%) male butchers and $10(52.6 \%)$ female butchers. The highest proportion of the samples contaminated by Salmonella sp. was obtained in the butchers of the age group 36-45 (55.7\%) followed by the age group 46-55 (23.0\%). Samples collected from the butchers of the age group 25-35 showed a lower prevalence of Salmonella sp. (9.8\%). Forty-five (26.2\%) samples collected from illiterate and 16 (57.1\%) samples collected from literate butchers were Salmonella positive. The higher contamination of Salmonella sp. was recovered from the butchers who seldom-washed knives and chopping boards (48.9\%), from those who used groundwater (52.6\%) and from the butchers without apron and gloves (52.8\%). A significant association was noted between the contamination of liver samples with the age, gender and literacy rate of butchers, type of water used, practices of washing knives and chopping board and wearing aprons and gloves $(p \leq 0.05)$ (Table 1). 


\section{Area-wise variation in the isolation of Salmonella}

Out of seven different locations the samples were collected from, the highest proportion of Salmonella sp. was recovered from Junhal Road (53.3\%) followed by Baseni (40.9\%) and Malpot Chowk (37.0\%). Samples collected from Hope Chowk showed the lowest prevalence of Salmonella (12.9\%) (Table 2).

\section{Antibiotic susceptibility pattern, MDR and ESBL Producers}

Amikacin was found to be the most effective antibiotic inhibiting the growth of $82.0 \%$ of the bacterial isolates followed by gentamicin which was sensitive to $75.4 \%$ of the isolates. All of the isolates were resistant to colistin. A large proportion of the isolates showed resistance to tetracycline $(96.7 \%)$ and azithromycin (77.0\%). Out of 61 isolates, 60 (98.8\%) isolates were found to be multidrug-resistant. The frequency of Salmonella isolates that gave ESBL screening test positive was found to be $33(54.1 \%)$. The confirmed ESBL production was reported in 29 (47.5\%) isolates (Table 3).

Table 1 Association of different attributes of butchers with the contamination of meat by Salmonella species 


\begin{tabular}{|c|c|c|c|c|}
\hline Attributes & & Frequency (\%) & Salmonella isolates (\%) & P-value \\
\hline \multirow[t]{2}{*}{ 1. Butcher's gender } & Male & 181 (90.5) & $51(28.2)$ & $\leq 0.05^{*}$ \\
\hline & Female & $19(9.5)$ & $10(52.6)$ & \\
\hline \multirow[t]{4}{*}{ 2. Butcher's age } & $25-35$ & $46(23.0)$ & $6(9.8)$ & $\leq 0.05^{*}$ \\
\hline & $36-45$ & $78(39.0)$ & $34(55.7)$ & \\
\hline & $46-55$ & $53(26.5)$ & $14(23.0)$ & \\
\hline & $>55$ & $23(11.5)$ & 7 (11.5) & \\
\hline \multirow[t]{2}{*}{ 3. Butcher's literacy rate } & Literate & $172(86.0)$ & $45(26.2)$ & $\leq 0.05^{*}$ \\
\hline & Illiterate & $28(14.0)$ & $16(57.1)$ & \\
\hline 4. Washing of knives & Washed frequently & 157 (78.5) & $40(25.5)$ & $\leq 0.05^{*}$ \\
\hline $\begin{array}{l}\text { and chopping } \\
\text { board }\end{array}$ & Seldom washed & $43(21.5)$ & 21 (48.9\%) & \\
\hline \multirow[t]{2}{*}{ 5. Water type used } & Municipal water & $181(90.5)$ & $51(28.2 \%)$ & $\leq 0.05^{*}$ \\
\hline & Ground water & $19(9.5)$ & $10(52.6 \%)$ & \\
\hline \multirow[t]{2}{*}{ 6. Use of apron/gloves } & Yes & $147(73.5)$ & $33(22.4 \%)$ & $\leq 0.05^{*}$ \\
\hline & No & $53(26.5)$ & $28(52.8 \%)$ & \\
\hline
\end{tabular}

*Significant at 5\% level of significance

Table 2 Area-wise variation in the isolation of Salmonella 


\begin{tabular}{|c|c|c|c|}
\hline Location & $\begin{array}{l}\text { No. of samples } \\
\text { examined }\end{array}$ & Salmonella positive samples (\%) & $S$. Typhi positive samples (\%) \\
\hline Baseni & 22 & $9(40.9)$ & $2(9.1)$ \\
\hline Dipendra & 35 & $9(25.7)$ & $2(5.7)$ \\
\hline \multicolumn{4}{|l|}{ Chowk } \\
\hline Hope Chowk & 31 & $4(12.9)$ & $2(6.4)$ \\
\hline Bel Chowk & 37 & $11(29.7)$ & $3(8.1)$ \\
\hline Malpot Chowk & 27 & $10(37.0)$ & $2(7.4)$ \\
\hline Gitanagar & 33 & $10(30.3)$ & $1(3.0)$ \\
\hline Junhal Road & 15 & $8(53.3)$ & $3(20.0)$ \\
\hline Total & 200 & 61 & 15 \\
\hline
\end{tabular}

Table 3 Antibiotic susceptibility pattern, MDR and ESBL Producers

\begin{tabular}{|c|c|c|c|c|c|c|c|}
\hline \multirow[t]{2}{*}{ SN } & \multirow[t]{2}{*}{ Antibiotics } & \multicolumn{3}{|c|}{$\begin{array}{c}\text { Antibiotic susceptibility } \\
\text { pattern }\end{array}$} & \multirow[t]{2}{*}{$\begin{array}{l}\text { MDR } \\
\text { isolates (\%) }\end{array}$} & \multicolumn{2}{|c|}{ ESBL producers } \\
\hline & & S (\%) & $\mathrm{R}(\%)$ & I (\%) & & $\begin{array}{l}\text { Screening test } \\
\text { positive (\%) }\end{array}$ & $\begin{array}{l}\text { Confirmed test } \\
\text { positive (\%) }\end{array}$ \\
\hline \multirow[t]{2}{*}{1} & Gentamicin & 46 & 12 & 3 & & & \\
\hline & & $(75.4)$ & (19.7) & $(4.9)$ & & & \\
\hline \multirow[t]{2}{*}{2} & Cotrimoxazole & 26 & 35 & 0 & & & \\
\hline & & (42.6) & (57.4) & (0) & & & \\
\hline \multirow[t]{2}{*}{3} & Ciprofloxacin & 31 & 14 & 16 & 60 (98.4) & $33(54.1)$ & 29 (47.5) \\
\hline & & (50.8) & $(23.0)$ & (26.8) & & & \\
\hline \multirow[t]{2}{*}{4} & Colistin & 0 & 61 & 0 & & & \\
\hline & & (0) & (100.0) & (0) & & & \\
\hline \multirow[t]{2}{*}{5} & Tetracycline & 2 & 59 & 0 & & & \\
\hline & & (3.3) & $(96.7)$ & (0) & & & \\
\hline \multirow[t]{2}{*}{6} & Azithromycin & 14 & 47 & 0 & & & \\
\hline & & $(23.0)$ & $(77.0)$ & (0) & & & \\
\hline \multirow[t]{2}{*}{7} & Amikacin & 50 & 0 & 11 & & & \\
\hline & & (82.0) & (0) & (18) & & & \\
\hline
\end{tabular}

S=sensitive $\mathrm{R}=$ resistant $\mathrm{I}=$ intermediate

\section{Discussion}

In the present study out of 200 samples, 61 (30.5\%) were Salmonella positive and 139 (69.5\%) were negative. Within the positive samples, 15 (7.5\%) were identified as S. Typhi and the remaining 46 (23.0\%) were other Salmonella species. This result showed a higher incidence of Salmonella than the study of 
Guptain which reported that the presence of Salmonella in layer chicken was 9.3\% [23]. Similarly, in a study in Yangzhou city, China, between April 2011 and March 2012, total 240 chicken carcasses were tested, and the overall contamination rate for Salmonella was 33.8\% [24]. However, the incidence of Salmonella in the present study is higher than a study by Shrestha et al who isolated $26.2 \%$ Salmonella in poultry meat in Chitwan district of Nepal [8]. In another study in the same district, $26.1 \%$ occurrence of Salmonella was reported from the poultry meat samples [25] which is lesser than the presence of Salmonella reported in the current study. These differences might be due to differences in geography, time and season of study among the researchers.

A large number of Salmonella sp. (52.6\%) was isolated from the meat collected from female butchers compared to male butchers (28.2\%). There was a significant association between the gender of the butchers with the number of Salmonella isolates $(p \leq 0.05)$. Females usually involve in household activities, children caring and cleanliness and mainly for various physiological reasons chances of microbes present in female might be comparatively more as compared to the male which may possibly lead them to be the carrier of bacteria and cause more contamination in the food products they handle [26][27]. The occurrence of Salmonella in the fresh chicken liver sample was significantly affected by age of butchers $(p \leq 0.05)$. In the current study, maximum contamination was found in the age group 36-45 years probably due to the lack of sanitation and personal hygiene because the people of this age group are mostly involved in children caring, raring and cleaning which might make them more likely to be contaminated with bacteria. The presence of Salmonella in liver samples was significantly affected by the literacy rate of butchers $(p \leq 0.05)$. This might be due to the lack of knowledge about the importance of sanitation in illiterate ones. In contrast, the literate butchers might know the importance of sanitation and so they use clean water and clean the slaughter area frequently [28]. The highest number of the sample (37) was collected from Bel Chowk area in which 11 (29.7\%) samples showed the presence of Salmonella including $3 S$. Typhi. The lowest number of samples (15) was collected from Junhal road area in which 8 (53.3\%) were positive to Salmonella including 3 S. Typhi. Most of the sample collected areas were densely populated and the butchers weren't aware of good hygienic practices while handling the poultry. In every location, they used bare dirty hands to slaughter the chicken which might be the reason for the contamination. A significant association was noted between the contamination of liver samples with water sources, practices of washing knives and chopping board and wearing aprons and gloves ( $\mathrm{p} \leq$ 0.05). Therefore, the use of municipal water, gloves, aprons, good hygienic environment of the slaughter house as well as proper personal hygiene of the butchers should be prioritized.

Amikacin was found to be the most effective antibiotic inhibiting the growth of 50 (82.0\%) bacteria followed by gentamicin which was able to inhibit 46 (75.4\%) isolates. Thus, amikacin and gentamicin can be used for the treatment against Salmonella species causing various diseases in human originated from the consumption of contaminated poultry products. Colistin was found to be $100.0 \%$ resistant which means it is not appropriate antibiotics for Salmonella. Moreover, the use of colistin has been banned due to their side effects of nephrotoxicity and neurotoxicity and has been replaced by other antibiotics [29]. In the present study, out of 61 isolates, only one Salmonella isolate was single drugresistant whereas 60 others were identified as multidrug-resistant. In a similar study by Dahal in 2007, out 
of 52 Salmonella isolates, $13.5 \%$ were reported to be MDR [30]. The frequency for ESBL producing Salmonella isolates was 29 (47.5\%). A similar study performed by Shrestha et al. detected $55.2 \%$ of the total Salmonella isolates were ESBL producers [8]. Moreover, similar research conducted by Wu et al. in China detected $8.6 \%$ of Salmonella sp. as ESBL producer which was very low compared to our study [31]. Extreme and haphazard use of broad-spectrum antibiotics might be associated with a higher rate of ESBL production in Salmonella.

\section{Conclusion}

The present study shows that chicken meat sold at Bharatpur Metropolis are contaminated with MDR and ESBL producing Salmonella sp. This suggests a dire need of taking initiatives to control the dissemination of such pathogens. Haphazard use of antibiotics, poor personal hygiene, illiteracy rate of the butchers, improper handling and storage practices are some of the factors concerned authorities should address.

\section{Limitations}

This study only determines the prevalence of Salmonella species and their MDR pattern with ESBL production. The source of contamination of meat was not assessed though. We were unable to perform the molecular characterization of bacteria due to the financial and laboratory scarcity. Future studies should address these limitations.

\section{Abbreviations}

SIM: sulfide indole motility; TSI: triple sugar iron; MR-VP: methyl-red Voges Proskauer; CLSI: Clinical and Laboratory Standards Institute; MHA: Mueller Hinton agar; XLD: Xylose lysine deoxycholate; ATCC: American type culture collection

\section{Declarations}

\section{Authors' contributions}

SA and SK conceived the concept and design of the study. BRS, AG, MC, DG, SS and SK performed experimental work. SA, SK and SS analyzed the data and prepared the final draft of the manuscript. All authors read and approved the final manuscript.

\section{Authors' details}

${ }^{1}$ Department of Microbiology, Birendra Multiple Campus, Tribhuvan University, Bharatpur, Chitwan, 44200, Nepal. 


\section{Acknowledgements}

The authors would like to express sincere appreciation to the Microbiology laboratory of Birendra Multiple campus for providing facilities to conduct this research work. We are indebted to all the butchers who provided chicken meat samples during the study.

\section{Competing interests}

All authors declare that they have no competing interests.

\section{Availability of data and materials}

All data obtained during this study are available within the article.

\section{Consent for publication}

Not applicable.

\section{Ethical approval and consent to participate}

Research Committee of Birendra Multiple Campus, Tribhuvan University, Nepal gave the approval to conduct this work. Animal samples were processed according to the animal research ethical guidelines. Verbal informed consent was obtained from all the butchers included in the study.

\section{Funding}

No specific funding was obtained for this work.

\section{References}

1. Shivaprasad HL. Fowl typhoid and pullorum disease. OIE Rev Sci Tech. 2000;19:405-24.

2. Murray CJ. Salmonellae in the environment. Rev Sci Tech. 1991;10:765-85.

3. Carramiñana JJ, Rota C, Agustín I, Herrera A. High prevalence of multiple resistance to antibiotics in Salmonella serovars isolated from a poultry slaughterhouse in Spain. Vet Microbiol. 2004;104:1339.

4. Soultos N, Koidis P, Madden RH. Presence of Listeria and Salmonella spp. in retail chicken in Northern Ireland. Lett Appl Microbiol. 2003;37:421-3. 
5. Hald T. Pathogen updates: Salmonella.foodborne infections and intoxications. 4th edition. San Diego: Elsevier Science; 2013.

6. Hirsh DC, Maclachlan NJ, Walker RL. Veterinary Microbiology. 2nd edition. Blackwell, USA.: Ames, lowa: Blackwell Pub., c2004.; 2004. https://trove.nla.gov.au/version/46532630.

7. Henson S. The Economics of Food Safety in Developing Countries. 2003.

8. Shrestha A, Bajracharya AM, Subedi H, Turha RS, Kafle S, Sharma S, et al. Multi-drug resistance and extended spectrum beta lactamase producing Gram negative bacteria from chicken meat in Bharatpur Metropolitan, Nepal. BMC Res Notes. 2017;10:1-5.

9. Yeung RM, Morris J. Consumer perception of food risk in chicken meat. Nutr Food Sci. 2001;31:2709.

10. Barrow GI, Feltham RKA. Cowan and Steel's Manual for the Identification of Medical Bacteria. 3rd edition. Cambridge University Press; 1993.

11. Guard-Petter J. The chicken, the egg and Salmonella enteritidis. Environ Microbiol. 2001;3:421-30.

12. Jones TF, Ingram LA, Cieslak PR, Vugia DJ, Tobin-D'Angelo M, Hurd S, et al. Salmonellosis Outcomes Differ Substantially by Serotype. J Infect Dis. 2008;198:109-14.

13. FAO. Poultry Meat \& Eggs. 00153 Rome, Italy; 2010. http://www.fao.org/3/al175e/al175e.pdf.

14. Nair DVT, Venkitanarayanan K, Johny AK. Antibiotic-resistant Salmonella in the food supply and the potential role of antibiotic alternatives for control. Foods. 2018;7.

15. Varma JK, Mølbak K, Barrett TJ, Beebe JL, Jones TF, Rabatsky-Ehr T, et al. Antimicrobial-Resistant Nontyphoidal Salmonella Is Associated with Excess Bloodstream Infections and Hospitalizations. J Infect Dis. 2005;191:554-61.

16. Van Duijkeren E, Wannet WJB, Houwers DJ, Van Pelt W. Antimicrobial susceptibilities of Salmonella strains isolated from humans, cattle, pigs, and chickens in The Netherlands from 1984 to 2001 . J Clin Microbiol. 2003;41:3574-8.

17. Pui CF, Wong WC, Chai LC, Lee HY, Tang JYH, Noorlis A, et al. Biofilm formation by Salmonella Typhi and Salmonella Typhimurium on plastic cutting board and its transfer to dragon fruit. Int Food Res J. 2011;18:31-8.

18. Yoke-Kqueen C, Learn-Han L, Noorzaleha AS, Son R, Sabrina S, Jiun-Horng S, et al. Characterization of multiple-antimicrobial-resistant Salmonella enterica Subsp. enterica isolated from indigenous vegetables and poultry in Malaysia. Lett Appl Microbiol. 2008;46:318-24.

19. Menghistu HT, Rathore R, Dhama K, Agarwal RK. Isolation, Identification and Polymerase Chain Reaction (PCR) Detection of Salmonella Species from Field Materials of Poultry Origin Scientist, Centre for Animal Disease Research and Diagnosis ( CADRAD), Senior Scientist, Avian Diseases Section, Di. Intl J Microbiol Res. 2011;2:135-42.

20. Clinical Laboratory Standards Institute (CLSI). Performance standards for antimicrobial susceptibility testing; 24th informational supplement (M100-S26). Wayne: CLSI; 2016. 
21. Magiorakos A, Srinivasan A, Carey RB, Carmeli Y, Falagas ME, Giske CG, et al. Multidrug-resistant, extensively drug-resistant and pandrug-resistant bacteria: an international expert proposal for interim standard definitions for acquired resistance. Clin Microbiol Infect. 2012;18:268-281.

22. Clinical Laboratory Standards Institute (CLSI). Performance standards for antimicrobial susceptibility testing: 21st informational supplement (M100-S22). Wayne: CLSl; 2012.

23. Gupta MP. Isolation and identification of Salmonella from layer chickens and eggs in Chitwan, Nepal. M. V.Sc. Thesis, Tribhuvan University, IAAS, Rampur, Nepal. 2006.

24. Li Q, Yin K, Xie X, Zhao F, Xia J, Chen Y, et al. Detection and CRISPR subtyping of Salmonella spp. isolated from whole raw chickens in Yangzhou from China. Food Control. 2017;82:291-7.

25. Acharya B. Isolation of Salmonella in poultry meat in Kathmandu, Lalitpur, Bhaktapur, Chitwan district. A B. V. Sc. and A. H. Internship thesis submitted to Tribhuvan University. 2007.

26. Khadka S, Adhikari S, Rai T, Ghimire U, Parajuli A. Bacterial contamination and risk factors associated with street-vended Panipuri sold in Bharatpur, Nepal. Int J Food Res. 2018;5:32-8.

27. Khadka S, Nshimiyimana JB, Thapa A, Akayezu V, Mwizerwa M, Woldetsadik AG. Bacterial profile of mobile phones used by college students in Kigali, Rwanda. Int J Appl Microbiol Biotechnol Res. 2018;6:87-94.

28. Sapkota S, Adhikari S, Pandey A, Khadka S, Adhikari M, Kandel H, et al. Multi-drug resistant extendedspectrum beta-lactamase producing $\mathrm{E}$. coli and Salmonella on raw vegetable salads served at hotels and restaurants in Bharatpur, Nepal. BMC Res Notes. 2019;12:516.

29. Loho T, Dharmayanti A. Colistin: an antibiotic and its role in multiresistant Gram-negative infections. Acta Med Indones. 2015;47:157-68.

30. Dahal N. Prevalence and antimicrobial resistance of Salmonella in imported chicken carcasses in Bhutan. National Cent Anim Health. Addis Ababa universiy. 2007;1:1-92.

31. Wu H, Xia X, Cui Y, Hu Y, Xi M, Wang X, et al. Prevalence of extended-Spectrum $\beta$-LactamaseProducing salmonella on retail chicken in six provinces and two national cities in the people's republic of china. J Food Prot. 2013;76:2040-4. 